\title{
GC-MS Based Metabolite Profiling, Antioxidant and Antimicrobial Properties of Different Solvent Extracts of Malaysian Plectranthus amboinicus Leaves
}

\author{
Mallappa Kumara Swamy, ${ }^{1}$ Greetha Arumugam, ${ }^{1}$ Ravinder Kaur, ${ }^{1}$ Ali Ghasemzadeh, ${ }^{1}$ \\ Mazina Mohd. Yusoff, ${ }^{2}$ and Uma Rani Sinniah ${ }^{1}$ \\ ${ }^{1}$ Department of Crop Science, Faculty of Agriculture, Universiti Putra Malaysia, 43400 Serdang, Selangor, Malaysia \\ ${ }^{2}$ Laboratory of Natural Products, Institute of Bioscience, Universiti Putra Malaysia, 43400 Serdang, Selangor, Malaysia
}

Correspondence should be addressed to Mallappa Kumara Swamy; swamy.bio@gmail.com and Uma Rani Sinniah; umarani@upm.edu.my

Received 8 December 2016; Accepted 9 March 2017; Published 23 March 2017

Academic Editor: Dolores García Giménez

Copyright (C) 2017 Mallappa Kumara Swamy et al. This is an open access article distributed under the Creative Commons Attribution License, which permits unrestricted use, distribution, and reproduction in any medium, provided the original work is properly cited.

\begin{abstract}
This study evaluates the phytochemistry, antioxidant, and antimicrobial effects of Plectranthus amboinicus leaves extracted in different solvents. The methanol extract contained the highest total phenolic $(94.37 \pm 1.24 \mathrm{mg}$ GAE/g) and flavonoid contents $(26.90 \pm 1.35 \mathrm{mg} \mathrm{RE} / \mathrm{g})$ and exhibited the highest DPPH scavenging activity $(90.13 \pm 3.32 \%)$ followed by the acetone extract $(80.23 \pm$ $3.26 \%)$ at $500 \mu \mathrm{g} / \mathrm{mL}$ concentration. Similarly, the highest ferric ion reduction potential $(849.63 \pm 30.95 \mu \mathrm{M}$ of Fe (II)/g dry weight) was exhibited by the methanol extract followed by the acetone extract $(695.92 \pm 25.44 \mu \mathrm{M}$ of Fe (II)/g dry weight). The methanol extract showed greater antimicrobial activity against all the tested pathogens (Bacillus subtilis, Methicillin-resistant Staphylococcus aureus, Pseudomonas aeruginosa, Escherichia coli, and Candida albicans). However, both hexane and acetone extracts failed to inhibit E. coli. S. aureus and C. albicans were more susceptible to all the extracts. Further, GC-MS analysis confirmed the occurrence of a total 46 phytocompounds in different solvent extracts. Some of the major compounds included carvacrol (37.7\%), tetracontane (16.6\%), squalene (15.6\%), tetrapentacontane (13.7\%), and Phytol (12.9\%). In conclusion, extraction solvents influenced the recovery of phytocompounds and the highest pharmacological activities of the methanol extract could be correlated to the presence of additional bioactive compounds.
\end{abstract}

\section{Introduction}

In nature, plants encompass a wide range of therapeutically valued bioactive compounds. These natural compounds are widely used in both traditional and modern therapies for improving human health with relatively less or no side effects. Globally, various medicinal plants have been well explored to discover novel drug molecules to combat the threat of everincreasing human diseases [1-3]. In the human body, cellular mechanisms lead to the generation of unstable compounds such as reactive oxygen species and free radicals, which can destroy living cells and may cause several clinical diseases. A range of synthetic and natural antioxidants are proved to be effective in controlling the activities of free radicals [4].
However, synthetic antioxidants cause adverse effects on the human body. Currently, though natural drugs are developed against human pathogens, the occurrence of drug resistance in microbes is posing a major challenge to the scientific community. Therefore, there is a need to discover novel drugs from the natural sources to benefit mankind. Plectranthus amboinicus (Lour.) Spreng. is a medicinal herb (Lamiaceae) which grows naturally in the subtropics and tropics of Africa, Asia, and Australia. The occurrence of about 30 nonvolatile and 76 volatile compounds attributes to its pharmacological properties such as anti-inflammatory, antimicrobial, wound healing, analgesic, antitumor, antiepileptic, antioxidant, and larvicidal actions [2]. Recent studies have suggested the success of this herb against oral, respiratory, skin, cardiovascular, 
digestive, and urinary diseases [2]. Previous studies have witnessed the existence of significant variations in secondary metabolites accumulation among the same plant species grown under diverse ecological conditions $[5,6]$. In general, various solvents are used for extracting plant metabolites from their different parts. Moreover, the extraction of phytocompounds and yield mainly depends on the type of solvents and the method of extraction [7]. Literature survey shows less information on phytochemicals and bioactivities of $P$. amboinicus plants growing under tropical conditions of Malaysia [8]. With this background, we investigated the influence of different solvents to recover higher phytochemicals from a local $P$. amboinicus plant leaves and assessed their polyphenols and antioxidant and antimicrobial activities. Further, GC-MS analysis was carried out to explain the occurrence of bioactive nonvolatile compounds in different solvent extracts.

\section{Materials and Methods}

2.1. Plant Material Collection. The wild growing P. amboinicus plant material was collected from the forest area near Universiti Putra Malaysia (UPM), Serdang, Selangor, Malaysia, during the month of August 2015. The plant was identified and authenticated taxonomically at the Department of Crop Science, UPM, Malaysia. The voucher specimen, PA-082015, was deposited in the department. The detached leaves from the collected plant materials were washed carefully under running tap water and dried for 1 week at room temperature in a shaded area. The dried leaves were finely powdered by using an electric blender and stored in a plastic bag container for further use at room temperature.

2.2. Preparation of Extracts. About 25 grams of powdered leaves of $P$. amboinicus were kept in a beaker to which $100 \mathrm{~mL}$ of various organic solvents (methanol, acetone, and hexane) was added and thoroughly shaken. Later, the mixture was placed at room temperature for $48 \mathrm{hrs}$ and stirred 2-3 times a day. After filtering the mixture, the filtrate was evaporated to dryness using rota-vapor. The final extracts were weighed to determine the yield (\%) and the dried extracts were stored at $4^{\circ} \mathrm{C}$ in a refrigerator for further studies.

\subsection{Determination of Total Phenolic Content in P. amboinicus} Extracts. Using the FC (Folin-Ciocalteu) colorimetric assay method, total phenolic content occurring in different solvent extracts of $P$. amboinicus leaves was evaluated [4]. Briefly, dried plant extract $(0.1 \mathrm{~g})$ was dissolved in $1 \mathrm{~mL}$ of distilled water. About $0.1 \mathrm{~mL}$ of this solution was later added to a solution containing $20 \%$ sodium carbonate solution $(1 \mathrm{~mL})$ and $50 \% \mathrm{FC}$ reagent $(0.5 \mathrm{~mL})$. This solution was mixed thoroughly and allowed to stand by at room temperature for $20 \mathrm{~min}$ to facilitate the reaction to occur. Afterwards, the absorbance of the solution was recorded at a wavelength of $730 \mathrm{~nm}$ against the blank (water). Likewise, a standard calibration curve was generated by using gallic acid (standard) at different concentrations. The gallic acid curve was used to convert the absorbance of different plant extracts into total phenolic content and expressed in mg GAE (gallic acid equivalents) per gram of dried solvent extract.

\subsection{Determination of Total Flavonoid Content in P. amboinicus} Extracts. The presence of total flavonoids content in various solvent extracts of $P$. amboinicus leaves was determined by using the colorimeter assay method as described by Swamy et al. [4]. In short, about $0.5 \mathrm{~mL}$ of the solvent extract $(1 \mathrm{mg} / \mathrm{mL})$ was suspended in $2 \mathrm{~mL}$ of distilled water and then added with $150 \mu \mathrm{L}$ of $5 \% \mathrm{NaNO}_{2}$ solution and incubated at room temperature for $5 \mathrm{~min}$. Thereafter, the solution was added to $2 \mathrm{~mL}$ of $\mathrm{NaOH}(4 \%)$ and $600 \mu \mathrm{L}$ of $\mathrm{AlCl}_{3}(10 \%)$ and made up to $5 \mathrm{~mL}$ using distilled water. The solution was mixed thoroughly and incubated for $15 \mathrm{~min}$ at room temperature. The absorbance of the solution was documented at a wavelength of $510 \mathrm{~nm}$ against the blank (water). In a similar way, a standard calibration curve was prepared by using the standard, rutin, at different concentrations. By using the standard curve of rutin, total flavonoid content was determined and expressed in mg of RE (rutin equivalents) per gram of dried solvent extract.

\subsection{In Vitro Antioxidant Activity Evaluation of P. amboinicus Extracts}

2.5.1. DPPH Free Radical Scavenging Assay. 1,1-Diphenyl-2picrylhydrazyl (DPPH) free radical scavenging assay was used to evaluate the antioxidant activity of different solvent extracts of $P$. amboinicus leaves as explained by Mohanty et al. [9] with minor modifications. In brief, different plant extract in the same volume $(0.3 \mathrm{~mL})$ at different concentrations ranging from 100 to $1000 \mu \mathrm{g} / \mathrm{mL}$ was added to $2 \mathrm{~mL}$ of DPPH solution $(0.1 \mathrm{mM})$ and placed in dark condition at room temperature for $30 \mathrm{~min}$. The absorbance of this solution was measured at a wavelength of $517 \mathrm{~nm}$ against the blank (methanol) by using UV-visible spectrophotometer. Ascorbic acid was used as the standard control. The percentage of inhibiting free radicals by each extracts was calculated by using the equation given below:

Inhibition activity (\%)

$$
\begin{aligned}
= & \frac{\text { Absorbance }(\text { control })-\text { Absorbance }(\text { extract })}{\text { Absorbance }(\text { control })} \\
& \times 100
\end{aligned}
$$

2.5.2. FRAP (Ferric Reducing Antioxidant Potential) Assay. FRAP assay was used to determine the total antioxidant activity of different solvent extracts of $P$. amboinicus leaves. Briefly, FRAP reagent was freshly prepared by mixing $2.5 \mathrm{~mL}$ of FeCl (20 mmol/L), $2.5 \mathrm{~mL}$ of $10 \mathrm{mmol} / \mathrm{L}$ TPTZ (2,4,6-tripyridylS-triazine), and $25 \mathrm{~mL}$ of $0.3 \mathrm{~mol} / \mathrm{L}$ acetate buffer $(\mathrm{pH}, 3.6)$ and incubated at $37^{\circ} \mathrm{C}$ under dark condition for $20 \mathrm{~min}$. Different solvent extracts $(2.0 \mathrm{~mL})$ were added into $2.0 \mathrm{~mL}$ of FRAP reagent and the final volume was made up to $10 \mathrm{~mL}$. The mixture was incubated at $25^{\circ} \mathrm{C}$ for 30 min under dark condition. The absorbance of the solution was recorded at $593 \mathrm{~nm}$ using acetate buffer as the blank. Results are expressed 
in $\mu \mathrm{M} \mathrm{Fe}$ (II)/g dry weight and equated with the standard, $\alpha$ tocopherol.

2.6. Determination of Antibacterial Activity. The test included a total of four bacterial species, namely, Bacillus subtilis B29, Methicillin-resistant Staphylococcus aureus (MRSA) (ATCC700698) (gram-positive), Pseudomonas aeruginosa (ATCC 15442), Escherichia coli E266 (gram-negative), and one fungal species, Candida albicans 90028. All microbial strains were procured from the Laboratory of Molecular Biomedicine, Institute of Bioscience, UPM, Serdang, Malaysia. The pure cultures of bacterial strains were subcultured onto Müller-Hinton Agar (MHA) while C. albicans 9002 was cultured on potato dextrose agar (PDA). The antibacterial properties of different solvent extracts of $P$. amboinicus leaves were evaluated by using disc diffusion method as described by Kumara et al. [10] with little modifications. In short, $10 \mathrm{mg}$ of each solvent extract was dissolved in $1 \mathrm{~mL}$ of dimethyl sulfoxide (DMSO) and about 10,20 , and $30 \mu \mathrm{L}$ of this solution were impregnated on $6 \mathrm{~mm}$ sized sterilized filter paper discs. Later, the air-dried discs were placed on individual MHA or PDA plates and previously preinoculated uniformly with a known bacterial or fungal strain, respectively. The discs saturated with DMSO $(20 \mu \mathrm{L})$ served as a negative control for all microbes while streptomycin $(100 \mathrm{mg} / \mathrm{mL})$ and nystatin $(100 \mathrm{mg} / \mathrm{mL})$ served as a positive control for bacterial and fungal species, respectively. All microbes were incubated in an incubator at $37^{\circ} \mathrm{C}$ for $24 \mathrm{hrs}$ to observe the zone of growth inhibition $(\mathrm{mm})$ around each disc. For each microbial strain, the experiment was repeated 3 times.

2.7. GC-MS Analysis. Each solvent extract was subjected to GC-MS analysis using the model instrument, GCMS-QP2010 Ultra (Shimadzu Co., Japan) attached with a capillary column DB-1 $(0.25 \mu \mathrm{m}$ film $\times 0.25 \mathrm{~mm} \mathrm{I}$. d. $\times 30 \mathrm{~m}$ length $)$. Analysis was performed by injecting $1 \mu \mathrm{L}$ of the sample with a split ratio of $20: 1$. Helium gas $(99.9 \%)$ was used as the carrier gas at a flow rate of $1 \mathrm{~mL} / \mathrm{min}$. The analysis was performed in the EI (electron impact) mode with $70 \mathrm{eV}$ of ionization energy. The injector temperature was maintained at $250^{\circ} \mathrm{C}$ (constant). The column oven temperature was set at $50^{\circ} \mathrm{C}$ (held for $3 \mathrm{~min}$ ), raised at $10^{\circ} \mathrm{C}$ per min to $280^{\circ} \mathrm{C}$ (held for $3 \mathrm{~min}$ ), and finally held at $300^{\circ} \mathrm{C}$ for $10 \mathrm{~min}$. The compounds were identified after comparing the spectral configurations obtained with that of available mass spectral database (NIST and WILEY libraries).

2.8. Statistical Analysis. In each experiment, the data recorded was from 3 replications $(n=3)$ and all the results are represented as mean $\pm \mathrm{SD}$. One-way analysis of variance (ANOVA) was carried out to compare the data. Further, to determine the statistically significant differences, Tukey's test was performed at $p<0.05$ level using GraphPad Prism (version 5.0) statistical software.

\section{Results}

The dry weight and final yield of the leaf extract were significantly affected by different solvents used for the extraction
TABLE 1: Dry weight and total yield of different solvent extracts of $P$. amboinicus leaves.

\begin{tabular}{lcc}
\hline Solvent extracts & Weight of the extract ${ }^{*}(\mathrm{mg} \pm \mathrm{SD})$ & Yield (\%) \\
\hline Methanol & $351.53 \pm 4.31^{\mathrm{a}}$ & 4.0 \\
Acetone & $111.6 \pm 3.01^{\mathrm{c}}$ & 1.0 \\
Hexane & $131.56 \pm 2.69^{\mathrm{b}}$ & 1.32
\end{tabular}

${ }^{*}$ Each value is expressed as mean \pm standard deviation (SD) $(n=3)$.

Values in the column followed by a different letter superscript are significantly different $(p<0.05)$.

TABLE 2: Total phenolics and flavonoids content of different solvent extracts of $P$. amboinicus leaves.

\begin{tabular}{|c|c|c|}
\hline Solvent extracts & $\begin{array}{c}\text { Total phenolic } \\
\text { content }^{*} \\
(\mathrm{mg} \mathrm{GAE} / \mathrm{g}) \pm \mathrm{SD}\end{array}$ & $\begin{array}{l}\text { Total flavonoid } \\
\text { content }^{*} \\
(\mathrm{mg} \mathrm{RE} / \mathrm{g}) \pm \mathrm{SD}\end{array}$ \\
\hline Methanol & $94.37 \pm 1.24^{\mathrm{a}}$ & $26.90 \pm 1.35^{\mathrm{a}}$ \\
\hline Acetone & $63.20 \pm 1.22^{\mathrm{c}}$ & $21.27 \pm 0.80^{\mathrm{b}}$ \\
\hline Hexane & $75.39 \pm 1.07^{\mathrm{b}}$ & $16.46 \pm 0.99^{c}$ \\
\hline
\end{tabular}

${ }^{*}$ Each value is expressed as mean \pm standard deviation (SD) $(n=3)$. Values in the column followed by a different letter superscript are significantly different $(p<0.05)$ and values having the same letters are not statistically significant $(p<0.05)$. GAE: gallic acid equivalent and RE: rutin equivalent.

(Table 1). The methanol solvent recorded the highest weight of the extract $(131.6 \pm 2.6 \mathrm{mg})$ and its yield $(1.3 \%)$. The extractable elements recovered from different solvents are in the following order, that is, methanol $>$ hexane $>$ acetone. Further, solvent extracts had a significant difference $(p<$ $0.05)$ in their total phenolic and total flavonoid content (Table 2). In the methanol leaf extract, the highest total phenolic content $(94.37 \pm 1.24 \mathrm{mg} \mathrm{GAE} / \mathrm{g})$ and flavonoid content $(26.9 \pm 1.3 \mathrm{mg} \mathrm{RE} / \mathrm{g})$ were recorded. In hexane extract, total phenolic content was found to be $75.39 \pm 1.07 \mathrm{mg} \mathrm{GAE} / \mathrm{g}$. However, total flavonoid content $(16.46 \pm 0.9 \mathrm{mg} \mathrm{RE} / \mathrm{g})$ was relatively lesser when compared to the acetone extract (21.27 $\pm 0.8 \mathrm{mg} \mathrm{RE} / \mathrm{g})$.

DPPH free radical scavenging property was observed to be dependent on the concentration for all the tested solvent extracts. The methanol extract exhibited the highest DPPH scavenging activity $(90.13 \pm 3.32 \%)$ followed by acetone extract $(80.23 \pm 3.26 \%)$ and hexane extract $(73.52 \pm 3.18 \%)$ at $500 \mu \mathrm{g} / \mathrm{mL}$ concentration (Figure 1).

However, DPPH scavenging activity of all extracts was inferior to the standard (ascorbic acid). Similar pattern of antioxidant activity was evidenced from FRAP assay method where the highest ferric ion reduction potential was exhibited by the methanol extract $(849.63 \pm 30.95 \mu \mathrm{M}$ of $\mathrm{Fe}$ (II)/g dry weight) followed by acetone extract with $695.92 \pm 25.44 \mu \mathrm{M}$ of $\mathrm{Fe}$ (II)/g dry weight (Figure 2). The lowest FRAP activity was observed in hexane extract $(376.98 \pm 15.42 \mu \mathrm{M}$ of Fe (II)/g dry weight). However, the superior activity was evidenced in the standard, $\alpha$-tocopherol.

The microbial inhibitory potential of different solvent extracts of $P$. amboinicus is depicted in Table 3. The results clearly showed the existence of a varied and selective antimicrobial activity of different solvent extracts against each microbial species tested. Further, increased concentration 
TABLE 3: Antibacterial activity of different solvent extracts of P. amboinicus at different concentrations.

\begin{tabular}{|c|c|c|c|c|c|}
\hline \multirow[b]{2}{*}{$\begin{array}{l}\text { Solvent extracts } \\
(\mu \mathrm{g} / \text { disc })\end{array}$} & \multicolumn{5}{|c|}{ Zone of inhibition* ${ }^{*}(\mathrm{~mm})$} \\
\hline & $\begin{array}{l}\text { Bacillus subtilis } \\
\text { B29 }\end{array}$ & $\begin{array}{c}\text { Staphylococcus aureus } \\
(M R S A)^{* *}\end{array}$ & $\begin{array}{c}\text { Pseudomonas } \\
\text { aeruginosa } \\
\text { ATCC } 15442\end{array}$ & $\begin{array}{c}\text { Escherichia coli } \\
\text { E266 }\end{array}$ & $\begin{array}{c}\text { Candida albicans } \\
90028\end{array}$ \\
\hline \multicolumn{6}{|l|}{ Hexane } \\
\hline 100 & $06.1 \pm 0.1$ & $08.0 \pm 0.3$ & $03.9 \pm 0.3$ & - & $06.1 \pm 0.2$ \\
\hline 200 & $06.9 \pm 0.4$ & $09.2 \pm 0.2$ & $06.0 \pm 0.2$ & - & $06.9 \pm 0.4$ \\
\hline 300 & $08.2 \pm 0.1$ & $10.0 \pm 0.3$ & $07.0 \pm 0.2$ & - & $07.9 \pm 0.3$ \\
\hline \multicolumn{6}{|l|}{ Methanol } \\
\hline 100 & $08.1 \pm 0.2$ & $07.1 \pm 0.5$ & $06.1 \pm 0.2$ & $06.0 \pm 0.2$ & $07.1 \pm 0.2$ \\
\hline 200 & $08.9 \pm 0.1$ & $08.0 \pm 0.5$ & $06.2 \pm 0.3$ & $07.4 \pm 0.5$ & $08.3 \pm 0.3$ \\
\hline 300 & $10.2 \pm 0.5$ & $09.2 \pm 0.3$ & $07.2 \pm 0.2$ & $08.7 \pm 0.6$ & $09.0 \pm 0.3$ \\
\hline \multicolumn{6}{|l|}{ Acetone } \\
\hline 100 & $01.9 \pm 0.1$ & $05.2 \pm 0.3$ & $02.2 \pm 0.2$ & - & $05.6 \pm 0.3$ \\
\hline 200 & $02.9 \pm 0.2$ & $06.1 \pm 0.4$ & $03.2 \pm 0.3$ & - & $06.0 \pm 0.2$ \\
\hline 300 & $03.0 \pm 0.1$ & $08.4 \pm 0.5$ & $03.9 \pm 0.2$ & - & $06.8 \pm 0.3$ \\
\hline
\end{tabular}

${ }^{*}$ The experiment included DMSO $(20 \mu \mathrm{L})$ as negative control while streptomycin $(100 \mathrm{mg} / \mathrm{mL})$ for bacteria and nystatin $(100 \mathrm{mg} / \mathrm{mL})$ for yeast served as positive control. Each value represents the mean \pm standard deviation (SD) of 3 replicates per treatment in 3 repeated experiments.

"-_" represents no activity observed.

${ }^{* *}$ MR represents Methicillin resistant.

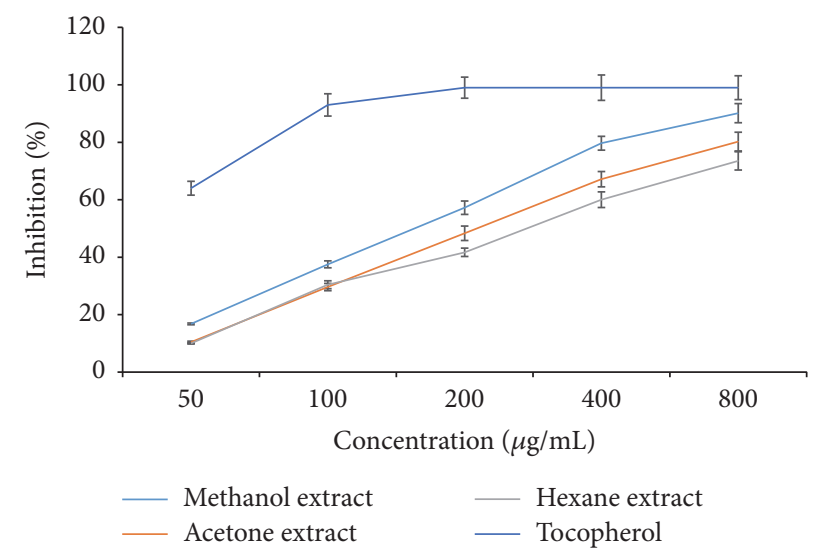

FIGURE 1: DPPH free radical scavenging activities of various solvent extracts of $P$. amboinicus.

of extracts evidenced relatively a higher activity in all the tested microbes irrespective of the solvent. Among all the tested microbes, S. aureus (MRSA) and C. albicans were more susceptible to all the extracts evaluated. The highest activity was observed in the methanol extract for $B$. subtilis $(10.2 \pm 0.5 \mathrm{~mm}), S$. aureus (MRSA) $(09.2 \pm 0.3 \mathrm{~mm}), P$. aeruginosa ATCC $15442(07.2 \pm 0.2 \mathrm{~mm})$, E. coli E266 (08.7 \pm $0.6 \mathrm{~mm})$, and C. albicans $(09.0 \pm 0.3 \mathrm{~mm})$ at a concentration of $300 \mu \mathrm{g} /$ disc. However, both hexane and acetone extracts failed to inhibit E. coli E266.

Further, GC-MS profiling of the extracts together revealed the occurrence of a total of 115 peaks of which about 46 chemical compounds were identified. These compounds

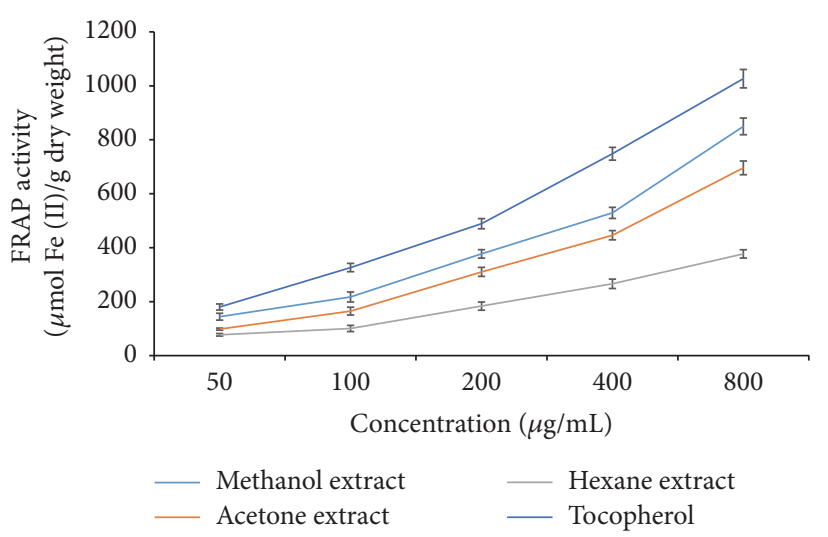

FIgURE 2: FRAP assay of various solvent extracts of $P$. amboinicus.

belong to different chemical classes and most of them are reported to exhibit important biological activities. Figure 3 shows the distinct chromatogram of $P$. amboinicus leaves extracted in different solvents. The identified compounds with their peak number, retention time (RT), and peak area (\%) are presented in Table 4. Out of 39 peaks observed in the chromatogram of methanol extract, 19 compounds were identified with 6 major peaks. The major compounds included tetracontane (16.6\%), tetrapentacontane $(11.3 \%)$, pentacosane $(7.8 \%)$, and n-hexadecanoic acid (4.9\%). Among the 26 peaks observed in the GC-MS profile of acetone extract, only 11 compounds were detected. The major compounds identified were Phytol (12.9\%), squalene (15.6\%), and $\beta$-Amyrin (5.3\%). While hexane extract profile revealed the presence of 16 detectable compounds from a total of 


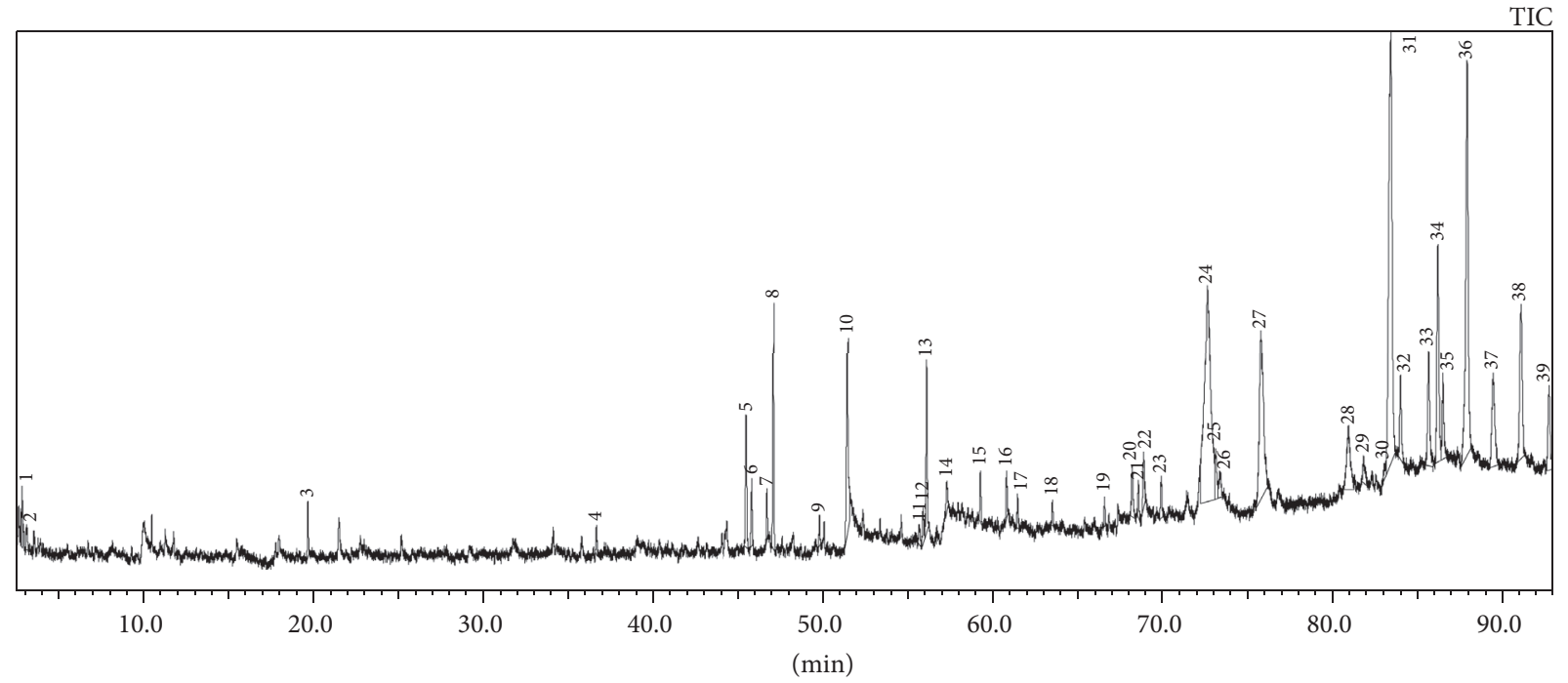

(a)

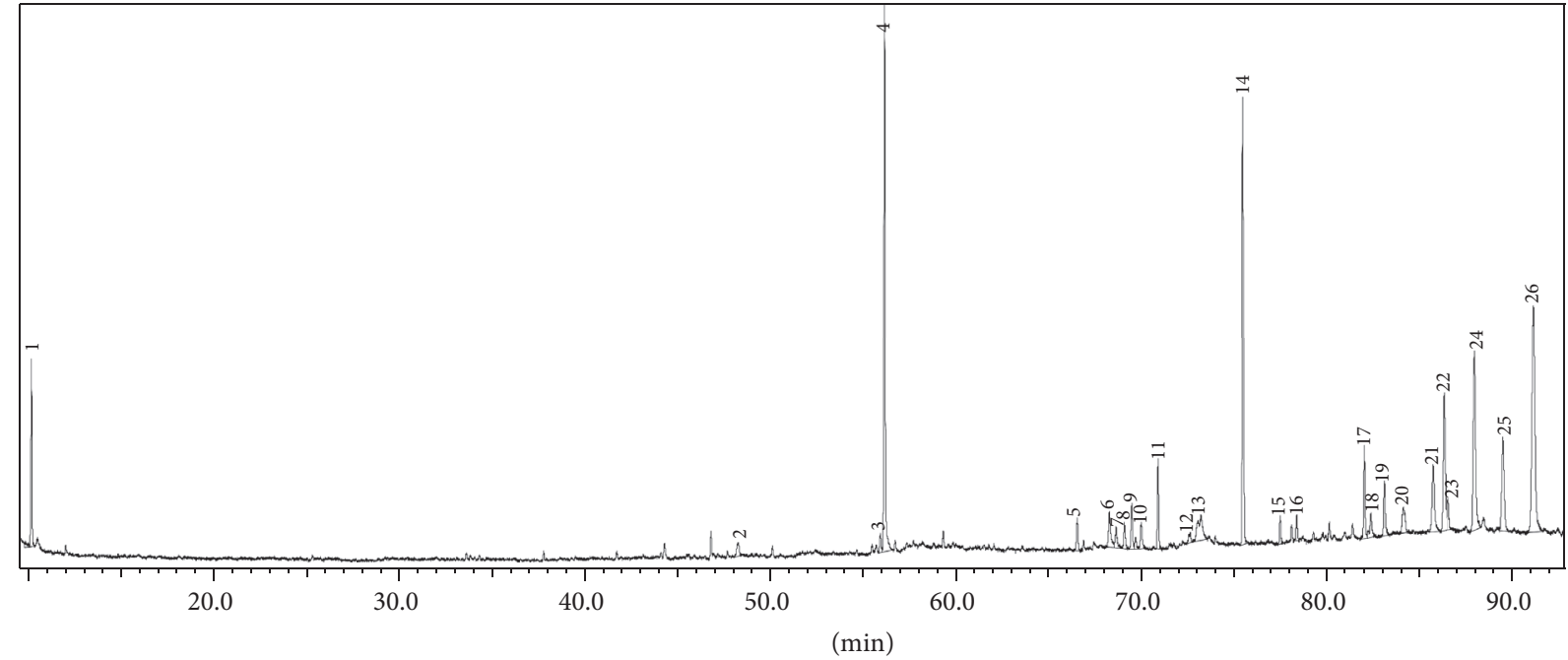

(b)

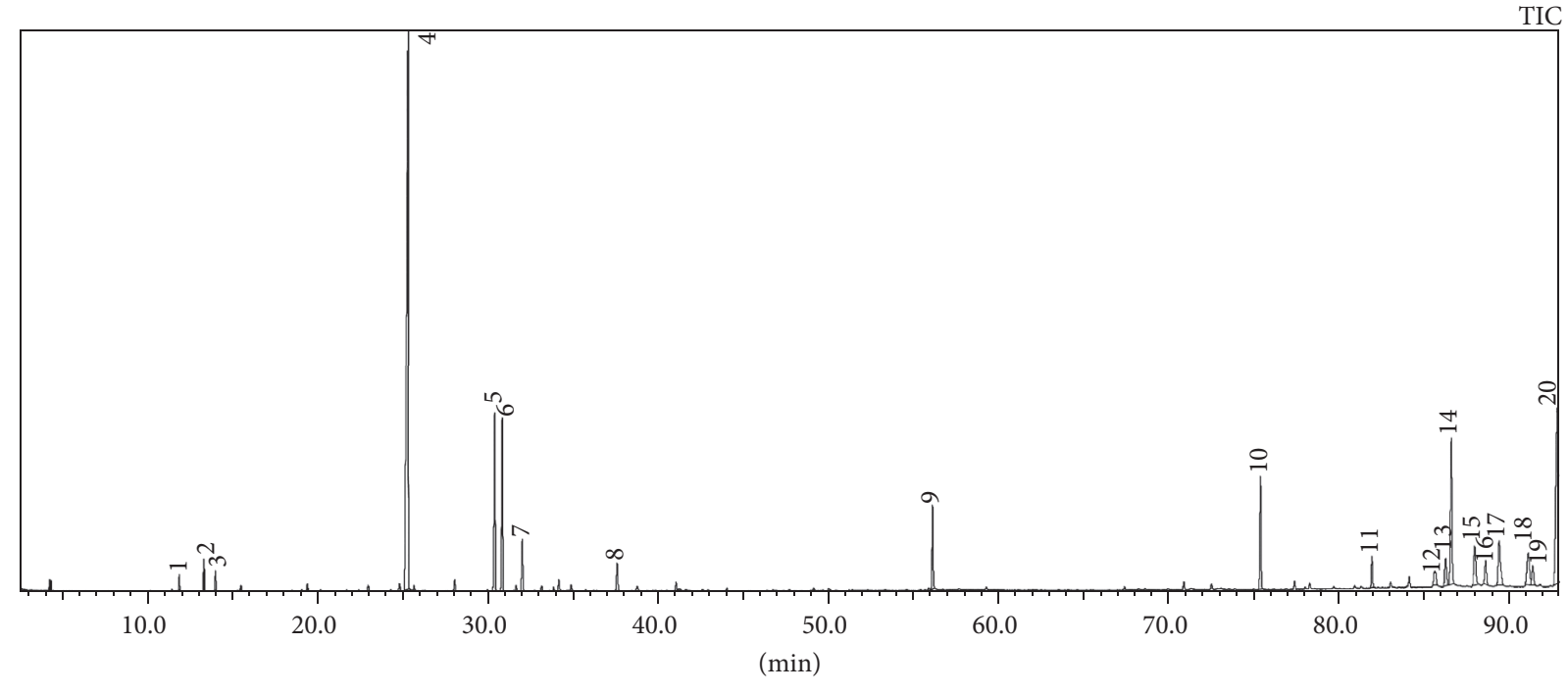

(c)

FigURE 3: GC-MS based chemical profiling of methanol (a), acetone (b), and hexane (c) extracts from P. amboinicus leaves. 
TABLE 4: GC-MS profile of different solvent extracts of P. amboinicus leaves.

\begin{tabular}{|c|c|c|c|c|}
\hline S. number & Name of the compound & Peak number & R. time & Peak area $(\%)$ \\
\hline \multicolumn{5}{|c|}{ Methanol extract } \\
\hline (1) & Butanoic acid, methyl ester & 2 & 03.14 & 00.35 \\
\hline (2) & 5-Methoxypyrrolidin-2-one & 3 & 19.69 & 00.72 \\
\hline (3) & (-)-Loliolide & 5 & 45.52 & 02.15 \\
\hline (4) & Neophytadiene & 7 & 46.75 & 00.81 \\
\hline (5) & 2-Pentadecanone, 6,10,14-trimethyl- & 8 & 47.11 & 03.01 \\
\hline (6) & 1-Decanol, 2-hexyl- & 9 & 49.84 & 00.49 \\
\hline (7) & n-Hexadecanoic acid & 10 & 51.46 & 04.97 \\
\hline (8) & Methyl (Z)-5,11,14,17-eicosatetraenoate & 12 & 55.93 & 00.50 \\
\hline (9) & Phytol & 13 & 56.13 & 03.30 \\
\hline (10) & Phytol, acetate & 15 & 59.30 & 00.61 \\
\hline (11) & Octanoic acid, 2-dimethylaminoethyl ester & 17 & 61.48 & 00.39 \\
\hline (12) & Carbonic acid, 2-dimethylaminoethyl isobutyl ester & 19 & 66.60 & 00.51 \\
\hline (13) & Di-n-octyl phthalate & 21 & 68.59 & 00.66 \\
\hline (14) & Tetrapentacontane & 24 & 72.63 & 11.32 \\
\hline (15) & Pentacosane & 27 & 75.78 & 07.88 \\
\hline (16) & Triacontane & 28 & 80.93 & 02.60 \\
\hline (17) & Tetracontane & 31 & 83.42 & 16.67 \\
\hline (18) & Squalane & 35 & 86.54 & 01.73 \\
\hline (19) & Methyl commate A & 38 & 91.08 & 01.96 \\
\hline \multicolumn{5}{|c|}{ Acetone extract } \\
\hline$(20)$ & 9,12-Octadecadienoyl chloride, (Z,Z)- & 3 & 55.93 & 00.63 \\
\hline$(21)$ & Phytol & 4 & 56.15 & 12.95 \\
\hline$(22)$ & Glycerol 1-palmitate & 6 & 68.25 & 01.73 \\
\hline$(23)$ & Di-n-octyl phthalate & 7 & 68.62 & 00.47 \\
\hline$(24)$ & (2,3-Diphenylcyclopropyl) methyl phenyl sulfoxide & 8 & 69.07 & 00.93 \\
\hline$(25)$ & Nerolidol propionate & 11 & 70.88 & 02.76 \\
\hline$(26)$ & Squalene & 14 & 75.454 & 15.64 \\
\hline$(27)$ & Nonacosane & 15 & 77.45 & 01.01 \\
\hline$(28)$ & 2,2,4-Trimethyl-3-(3,8,12,16-tetramethyl-heptadeca-3,7,11,15-tetraenyl)-cyclohexanol & 16 & 78.34 & 00.86 \\
\hline (29) & Hentriacontane & 17 & 81.98 & 03.37 \\
\hline$(30)$ & $\beta$-Amyrin & 25 & 89.50 & 05.34 \\
\hline \multicolumn{5}{|c|}{ Hexane extract } \\
\hline (31) & Benzene, 1-methyl-3-(1-methylethyl)- & 1 & 11.91 & 00.49 \\
\hline$(32)$ & $\gamma$-Terpinene & 2 & 13.37 & 01.03 \\
\hline$(33)$ & trans Sabinene hydrate & 3 & 14.04 & 00.66 \\
\hline$(34)$ & Carvacrol & 4 & 25.32 & 37.73 \\
\hline$(35)$ & trans-caryophyllene & 5 & 30.40 & 07.37 \\
\hline$(36)$ & $\alpha$-Humulene & 7 & 32.03 & 02.15 \\
\hline$(37)$ & Caryophyllene oxide & 8 & 37.59 & 01.00 \\
\hline$(38)$ & Phytol & 9 & 56.13 & 03.19 \\
\hline (39) & Squalene & 10 & 75.43 & 04.75 \\
\hline$(40)$ & Pentacosane & 11 & 81.95 & 00.86 \\
\hline$(41)$ & Stigmasterol & 13 & 86.25 & 01.29 \\
\hline$(42)$ & Tetratriacontane & 14 & 86.57 & 08.80 \\
\hline (43) & Hexatriacontane & 16 & 88.57 & 01.02 \\
\hline$(44)$ & $\alpha$-Amyrin & 18 & 91.07 & 01.53 \\
\hline$(45)$ & Hexatriacontane & 19 & 91.33 & 01.47 \\
\hline$(46)$ & Tetrapentacontane & 20 & 92.76 & 13.77 \\
\hline
\end{tabular}


20 peaks, including carvacrol (37.7\%), trans-caryophyllene $(7.3 \%)$, squalene $(4.7 \%)$, tetrapentacontane $(13.7 \%)$, and tetratriacontane $(8.8 \%)$ as the major components.

\section{Discussion}

Recent years have witnessed the importance of phytochemicals due to their remarkable health benefits. Plant metabolites are extracted by using various ways, such as maceration, decoction, soxhlet extraction, microwave-assisted extraction, supercritical fluid extraction, and ultrasound-assisted extraction method. As maceration technique is a simple and the easiest method, it is widely used at the preliminary research level [11]. The efficiency of extraction depends on several factors, including the nature of phytochemical constituents, the method of extraction, particle size of the sample, extraction time, temperature, $\mathrm{pH}$, solute to solvent ratio, and the solvent polarity [12]. The appropriate use of solvent system is crucial in order to recover higher extract yield, polyphenols, and some other bioactive compounds from a sample [13]. Plant derived polyphenols including flavonoids possess several biological properties and thus necessitate evaluating their presence in different plant parts extracted in different organic solvents $[4,14,15]$. This study revealed the existence of a significant difference in the extract yield obtained by different solvents. Further, the highest extract yields and total phenolic content obtained in the methanolic leaf extract of $P$. amboinicus could be attributed to its high polarity [13]. Another possible reason might be due to the establishment of complexes by phenolic constituents with other biomolecules such as proteins, carbohydrates, terpenes, and inorganic compounds that can be more easily recovered from methanol in comparison to other solvents [16]. Similarly, the use of methanol as the best solvent for extraction is well documented in the literature $[4,13,17]$. On the contrary, methanol, acetone, and water are reported to be ineffective for extracting polyphenols from the seeds of grapes [18]. In the present study, the extractive yield and total phenolic content were better evidenced in the nonpolar hexane extract when compared to the polar solvent, acetone. In contrast, the hexane extract yielded much lesser total flavonoid content compared to the acetone extract. This difference in the extract yields could be attributed to the occurrence of a wide range of diverse phytochemical components in $P$. amboinicus leaves and differences in the solvent polarity. Furthermore, it is reported that the level of solubility of a phenolic compound decides the recovery percentage of a particular solvent type $[4,13]$. In contrast, according to the report by Bhatt and Negi, [19], the acetone extract contained significantly higher total phenolics compared to the methanol or hexane extracts, which was endorsed for the difference in the geographic location and other environmental factors [20]. Likewise, earlier study has identified the presence of polyphenols such as caffeic acid, coumaric acid, rutin, quercetin, and gallic acid in the acetone leaf extract of $P$. amboinicus [21]. As there is a dearth of scientific details on phytochemistry of Malaysian P. amboinicus, this study will be certainly appreciated. In general, this study suggests the use of methanol and hexane solvents for higher recovery of extractable compound from P. amboinicus leaves. Because of the lower extractive yield obtained in this study, it is recommended to use other better extraction methods in $P$. amboinicus. Nevertheless, it is reported that the biological properties depend not only on the total extract yield but also on its phytochemical composition [22].

In the human body, cell damage may induce the generation of increased levels of free radicals. Various disorders including myocardial infarction, cancer, atherosclerosis, and neurogenerative disorders are mainly correlated to these free radicals [4]. Antioxidants are chemical compounds and have the ability to prevent various oxidative stress related cell damages mediated by free radicals. Many antioxidant molecules are recorded in several medicinal plants and thus will be beneficial in the treatment of several human diseases [15]. Most frequently, the DPPH and FRAP assay methods are preferred for determining antioxidant activity [9]. In this study, radical scavenging activity was observed to be concentration dependent and corroborates with the previous reports on several other plant species $[4,9,23]$. The superior radical scavenging potential of plant solvent extracts may be interrelated to the presence of various antioxidants such as polyphenolic compounds [14, 23]. Even though earlier reports have stated that $P$. amboinicus leaf extracts possess antioxidant properties [2], none of them have reported the systematic study comparing the effect of different solvents on the antioxidant potential of $P$. amboinicus species growing under tropical conditions of Malaysia. The methanol extract was found to exhibit the highest scavenging activity when compared to other solvent extracts. This could be attributed to the fact that the methanol extract possesses higher antioxidant molecules such as phenolic compounds as evidenced by our phytochemical analysis (Table 2). In contrast, Bhatt and Negi [19] reported that acetone extract of $P$. amboinicus possessed superior antioxidant activity when compared to hexane, ethyl acetate, or methanol extracts. According to Rai et al. [24], the effective antioxidant activity of $P$. amboinicus leaves was observed when extracted with the solvent, ethanol. This difference could be could be due to differences in the geographical growth conditions as stated previously by Swamy et al. [4]. As stated by the earlier reports, the free radical scavenging activity of different solvent extracts of plants mainly depends on the existence of different bioactive chemical constituents $[1,5]$. Further, more polar solvents can often extract antioxidant compounds in higher quantities. Overall, high-polarity solvent (methanol) was very effective in extracting more antioxidant compounds when compared to an intermediate polar solvent, acetone, and nonpolar solvent, hexane.

Antimicrobial agents (synthetic or plant based) effectively kill a wide range of infectious microbes. However, their improper and overuse has permitted microbes to develop multidrug resistance ability which is a major threat and a bigger challenge to the medical world [25]. Hence, there is a need to investigate novel molecules to overcome antimicrobial resistance. Further, present research emphasizes on the development of plant based drugs due to the fact that synthetic drugs cause several side effects in humans. In this regard, we evaluated the antimicrobial properties of $P$. amboinicus leaf extracts and the results were very conclusive. All the tested 
microorganisms were effectively inhibited by all solvent extracts with the exception of a gram-negative bacteria $E$. coli, which was inhibited only by the methanolic leaf extract. MRSA strain exhibited less susceptibility to all solvent extracts when compared to other gram-positive strains. $B$. subtilis was highly susceptible to the methanol extract. Interestingly, methicillin-resistant S. aureus and C. albicans were highly susceptible to all the extracts. Similarly, Gurgel et al. [26] reported the efficacy of the hydroalcoholic leaf extracts of $P$. amboinicus from Brazil against MRSA strains while Manjamalai et al. [27] report the anticandidal activity of the methanolic leaf extract of Indian P. amboinicus. To support this, researchers have stated that mostly gram-negative bacteria exhibit more resistant properties against a wide range of antibiotics or chemical drugs when compared to grampositive bacteria $[19,28]$. This difference in the susceptibility of a microbe to plant extracts is also linked to differences in their cell wall and outer membrane structures [29]. MRSA cause several human health problems including skin infections, sepsis, pneumonia and other infections, and C. albicans is a prime causative agent of candidiasis. Thus, $P$. amboinicus leaf extracts may be beneficial in treating these diseases causing microbes. Microbial inhibition was found to vary with the type of solvent extracts evaluated. Likewise, previous researchers also have testified the wide-ranging antimicrobial activity of this plant $[2,19]$. However, these results contradict with the findings by Bhatt and Negi [19], where the superior antimicrobial activity was shown by the acetone extract, while Jiyauddin et al. [8] report the highest antimicrobial activity in the ethanolic leaf extract. This discrepancy could be due to differences in the extraction methods and microbes tested. The highest antimicrobial activity of methanol extract against all the examined microorganisms could be due to more soluble bioactive compounds extracted in the methanol solvent. These bioactive compounds, perhaps, may inhibit microbial growth effectively by binding to their cell surface. In support of this, previous studies have stated that the antimicrobial action of plant extract is presumably related to the collective effect of phenolic compounds adsorption onto the cell membrane leading to its disruption and cell leakages and the generation of hydroperoxides by phenolic compounds $[2,30]$. These results support the reports emphasizing on the curative property of $P$. amboinicus plant extracts and its essential oil [2]. However, most of the research studies have evaluated antimicrobial activities of essential oil of $P$. amboinicus and limited importance is given on different plant extracts, especially, in those plants growing under Malaysian conditions $[2,8,20,26,27,31]$. Furthermore, this study establishes the importance of the solvents in recovering higher extractable compounds with potent antimicrobial action against human pathogens for the first time.

Various biological activities of $P$. amboinicus leaf extract can be described by investigating the chemical composition of each extract using GC-MS analysis. The literature survey reveals the occurrence of about 30 nonvolatiles from methanol, ethyl acetate, water, and chloroform extracts of $P$. amboinicus leaves, stems, and roots around the world [2, 19, 32]. However, to the best of our knowledge, there is no report of GC-MS based metabolite profiling to detect the presence of various bioactive compounds in hexane and acetone extracts of $P$. amboinicus leaves. In addition, compounds in different solvent extracts of Malaysian P. amboinicus plants are yet to be studied. Accordingly, GC-MS analysis was performed in the preset study and identified a total of 46 compounds from different solvent extracts. The highest number of compounds (19) was evidenced in the methanolic leaf extract followed by a hexane extract (16) and acetone extract (11). Most of these compounds are known to exhibit various pharmacological activities. In this study, the higher antioxidant and antimicrobial activities of the methanol extract could be correlated to the occurrence of more number of bioactive compounds including n-hexadecanoic acid, Phytol, and squalane. Similarly, the occurrence of these compounds is also evidenced in many medicinal plants leaves extracted with methanol $[5,33,34]$. Phytol is an important diterpene that possesses antimicrobial, antioxidant, and anticancer activities $[5,35$, 36]. Hexadecanoic acid is known to exhibit strong antimicrobial and anti-inflammatory activity [5, 37]. Squalene is a triterpene that act as natural antioxidants and possess various pharmacological importance [38, 39]. Neophytadiene is a good analgesic, antipyretic, anti-inflammatory, antimicrobial, and antioxidant compound [33]. Similarly, the compounds $\alpha$ and $\beta$-Amyrin present in hexane and methanol extracts are known to possess antidiabetic, anti-inflammatory, antiarthritic, and anticancer activities [34]. The presence of compounds such as carvacrol, caryophyllene oxide, and stigmasterol in hexane extract is also reported with various biological activities [2, 33]. Similarly, Kunle et al. [39] also showed the occurrence of carvacrol in the hexane extract of Lippia multiflora leaves and showed potent antimicrobial activity [39]. Carvacrol, an isoprenyl phenol is reported as one of the strongest antimicrobial agents [40]. Moreover, it has shown to inhibit the biofilms formation by Chromobacterium violaceum, Typhimurium DT104, Salmonella enterica, and Staphylococcus aureus [41]. The compound, caryophyllene oxide, exhibits a wide range of antimicrobial properties [42]. Likewise, a steroid compound was also isolated from the hexane extract of Hydnophytum formicarum [43]. In the same study, stigmasterol was shown to possess better antimicrobial and antioxidative properties. This could be one of the reasons for the higher antimicrobial activity exhibited by hexane extract compared to acetone extract as stated earlier. However, some of the other major compounds, including tetracontane, pentacosane, tetratriacontane, tetrapentacontane, and hentriacontane, are yet to be described in detail. Nevertheless, more research efforts are required to isolate, characterize, and evaluate these compounds from $P$. amboinicus leaves to validate their various pharmacological importance.

\section{Conclusion}

In this study, the presence of various soluble bioactive compounds in $P$. amboinicus leaf extracts greatly contributed to antioxidant and antimicrobial activities. Phytochemical composition and yield of the extract varied depending on the solvent types used for the extraction. In the methanolic extract, more soluble phytocompounds were noticed. The 
results clearly support the use of $P$. amboinicus in traditional medicinal practices to treat various diseases. Thus, this plant can serve as a new natural source for obtaining many therapeutically valued metabolites against various diseases.

\section{Conflicts of Interest}

The authors declare that they have no conflicts of interest.

\section{Acknowledgments}

The authors sincerely thank Department of Crop Science and Laboratory of Natural Products, Universiti Putra Malaysia, for providing laboratory facilities.

\section{References}

[1] P. Kuppusamy, M. M. Yusoff, N. R. Parine, and N. Govindan, "Evaluation of in-vitro antioxidant and antibacterial properties of Commelina nudiflora L. extracts prepared by different polar solvents," Saudi Journal of Biological Sciences, vol. 22, no. 3, pp. 293-301, 2015.

[2] G. Arumugam, M. K. Swamy, and U. R. Sinniah, "Plectranthus amboinicus (Lour.) Spreng: botanical, phytochemical, pharmacological and nutritional significance," Molecules, vol. 21, no. 4, p. 369, 2016.

[3] M. K. Swamy and U. R. Sinniah, "Patchouli (Pogostemon cablin Benth.): botany, agrotechnology and biotechnological aspects," Industrial Crops and Products, no. 87, pp. 161-176, 2016.

[4] M. K. Swamy, U. R. Sinniah, and M. S. Akhtar, "In vitro pharmacological activities and GC-MS analysis of different solvent extracts of Lantana camara leaves collected from tropical region of Malaysia," Evidence-Based Complementary and Alternative Medicine, vol. 2015, Article ID 506413, 9 pages, 2015.

[5] M. K. Swamy and U. R. Sinniah, "A comprehensive review on the phytochemical constituents and pharmacological activities of Pogostemon cablin Benth.: an aromatic medicinal plant of industrial importance," Molecules, vol. 20, no. 5, pp. 8521-8547, 2015.

[6] I. Sellem, F. Kaaniche, A. M. Chakchouk, and L. Mellouli, "Antioxidant, antimicrobial and anti-acetylcholinesterase activities of organic extracts from aerial parts of three Tunisian plants and correlation with polyphenols and flavonoids contents," Bangladesh Journal of Pharmacology, vol. 11, no. 2, pp. 531-544, 2016.

[7] E. A. Hayouni, M. Abedrabba, M. Bouix, and M. Hamdi, "The effects of solvents and extraction method on the phenolic contents and biological activities in vitro of Tunisian Quercus coccifera L. and Juniperus phoenicea L. fruit extracts," Food Chemistry, vol. 105, no. 3, pp. 1126-1134, 2007.

[8] K. Jiyauddin, A. D. Samer, T. Darashhni et al., "Comparison of antibacterial activity of Ocimum tenuiflorum L. and Plectranthus amboinicus (Lour.) Spreng against the clinical pathogens Staphylococcus aureus, Pseudomonas aeruginosa and Escherichiacoli," World Journal of Pharmaceutical Research, vol. 4, no. 3, pp. 1887-1901, 2015.

[9] S. K. Mohanty, K. S. Mallappa, A. Godavarthi et al., "Evaluation of antioxidant, in vitro cytotoxicity of micropropagated and naturally grown plants of Leptadenia reticulata (Retz.) Wight \& Arn.-an endangered medicinal plant," Asian Pacific Journal of Tropical Medicine, vol. 7, supplement 1, pp. S267-S271, 2014.
[10] S. M. Kumara, K. M. Sudipta, P. Lokesh et al., "Phytochemical screening and in vitro antimicrobial activity of Bougainvillea spectabilis flower extracts," International Journal of Phytomedicine, vol. 4, no. 3, pp. 375-379, 2012.

[11] N. N. Azwanida, "A review on the extraction methods use in medicinal plants, principle, strength and limitation," Medicinal \& Aromatic Plants, vol. 4, no. 3, article 196, 2015.

[12] Q. D. Do, A. E. Angkawijaya, P. L. Tran-Nguyen et al., "Effect of extraction solvent on total phenol content, total flavonoid content, and antioxidant activity of Limnophila aromatica," Journal of Food and Drug Analysis, vol. 22, no. 3, pp. 296-302, 2014.

[13] S. B. Iloki-Assanga, L. M. Lewis-Luján, C. L. Lara-Espinoza et al., "Solvent effects on phytochemical constituent profiles and antioxidant activities, using four different extraction formulations for analysis of Bucida buceras L. and Phoradendron californicum Complementary and Alternative Medicine," BMC Research Notes, vol. 8, no. 1, article 396, 2015.

[14] C. L. Apetrei, C. Tuchilus, A. C. Aprotosoaie, A. Oprea, K. E. Malterud, and A. Miron, "Chemical, antioxidant and antimicrobial investigations of Pinus cembra L. bark and needles," Molecules, vol. 16, no. 9, pp. 7773-7788, 2011.

[15] R. A. Gonbad, A. Afzan, E. Karimi, U. R. Sinniah, and M. K. Swamy, "Phytoconstituents and antioxidant properties among commercial tea (Camellia sinensis L.) clones of Iran," Electronic Journal of Biotechnology, vol. 18, no. 6, pp. 433-438, 2015.

[16] A. K. Esmaeili, R. M. Taha, S. Mohajer, and B. Banisalam, "Antioxidant activity and total phenolic and flavonoid content of various solvent extracts from in vivo and in vitro grown Trifolium pratense L. (Red Clover)," BioMed Research International, vol. 2015, Article ID 643285, 11 pages, 2015.

[17] B. Sultana, F. Anwar, and M. Ashraf, "Effect of extraction solvent/technique on the antioxidant activity of selected medicinal plant extracts," Molecules, vol. 14, no. 6, pp. 2167-2180, 2009.

[18] G. K. Jayaprakasha, R. P. Singh, and K. K. Sakariah, “Antioxidant activity of grape seed (Vitis vinifera) extracts on peroxidation models in vitro," Food Chemistry, vol. 73, no. 3, pp. 285-290, 2001.

[19] P. Bhatt and P. S. Negi, "Antioxidant and Antibacterial Activities in the Leaf Extracts of Indian Borage (Plectranthus amboinicus)," Food and Nutrition Sciences, vol. 03, no. 02, pp. 146-152, 2012.

[20] M. N. Erny Sabrina, M. Razali, A. H. S. Mirfat, and M. A. Mohd Shukri, "Antimicrobial activity and bioactive evaluation of Plectranthus amboinicus essential oil," American Journal of Research Communication, vol. 2, no. 12, pp. 121-127, 2014.

[21] S. K. Gupta, P. Bhatt, G. S. Joseph, P. S. Negi, and M. C. Varadaraj, "Phenolic constituents and biological activities of leaf extracts of traditional medicinal plant Plectranthus amboinicus Benth (Lamiaceae)," TANG (Humanitas Medicine), vol. 3, no. 4, pp. 32.1-32.6, 2013.

[22] H. Padalia and S. Chanda, "Antimicrobial efficacy of different solvent extracts of Tagetes erecta L. flower, alone and in combination with antibiotics," Applied Microbiology: Open Access, vol. 1, article 106, 2015.

[23] R. Naz and A. Bano, "Phytochemical screening, antioxidants and antimicrobial potential of Lantana camara in different solvents," Asian Pacific Journal of Tropical Disease, vol. 3, no. 6, pp. 480-486, 2013. 
[24] V. Rai, V. Pai, and P. Kedilaya, "A preliminary evaluation of anticancer and antioxidant potential of two traditional medicinal plants from Lamiaceae-Pogostemon heyneanus and Plectranthus amboinicus," Journal of Applied Pharmaceutical Science, vol. 6 , no. 8, pp. 73-78, 2016.

[25] G. R. Rudramurthy, M. K. Swamy, U. R. Sinniah, and A. Ghasemzadeh, "Nanoparticles: alternatives against drug-resistant pathogenic microbes," Molecules, vol. 21, no. 7, article 836, 2016.

[26] A. P. A. D. Gurgel, J. G. da Silva, A. R. S. Grangeiro et al., "Antibacterial effects of Plectranthus amboinicus (Lour.) spreng. (Lamiaceae) in methicillin resistant Staphylococcus aureus (MRSA)," Latin American Journal of Pharmacy, vol. 28, no. 3, pp. 460-464, 2009.

[27] A. Manjamalai, T. Alexander, and V. M. Berlin Grace, "Bioactive evaluation of the essential oil of Plectranthus amboinicus by GC-MS analysis and its role as a drug for microbial infections and inflammation," International Journal of Pharmacy and Pharmaceutical Sciences, vol. 4, no. 3, pp. 205-211, 2012.

[28] N. Pokharen, S. Dahal, and M. Anuradha, "Phytochemical and antimicrobial studies of leaf extract of Euphorbia neriifolia," Journal of Medicinal Plants Research, vol. 5, no. 24, pp. 57855788, 2011.

[29] T. J. Silhavy, D. Kahne, and S. Walker, "The bacterial cell envelope," Cold Spring Harbor Perspectives in Biology, vol. 2, no. 5, Article ID a000414, 2010.

[30] M. Akagawa, T. Shigemitsu, and K. Suyama, "Production of hydrogen peroxide by polyphenols and polyphenol-rich beverages under quasi-physiological conditions," Bioscience, Biotechnology and Biochemistry, vol. 67, no. 12, pp. 2632-2640, 2003.

[31] J. G. M. Da Costa, C. K. B. Pereira, F. F. G. Rodrigues, and S. G. De Lima, "Chemical composition, antibacterial and fungicidal activities of leaf oil of Plectranthus amboinicus (Lour.) Spreng," Journal of Essential Oil Research, vol. 22, no. 2, pp. 183-185, 2010.

[32] S. S. El-Hawary, R. H. El-Sofany, A. R. Abdel-Monem, R. S. Ashour, and A. A. Sleem, "Polyphenolics content and biological activity of Plectranthus amboinicus (Lour.) spreng growing in Egypt (Lamiaceae)," Pharmacognosy Journal, vol. 4, no. 32, pp. 45-54, 2012.

[33] B. Venkata Raman, L. A. Samuel, M. Pardha Saradhi et al., "Antibacterial, antioxidant activity and GC-MS analysis of Eupatorium odoratum," Asian Journal of Pharmaceutical and Clinical Research, vol. 5, no. 2, pp. 99-106, 2012.

[34] G. Ghosh, P. Panda, M. Rath, A. Pal, T. Sharma, and D. Das, "GC-MS analysis of bioactive compounds in the methanol extract of Clerodendrum viscosum leaves," Pharmacognosy Research, vol. 7, no. 1, pp. 110-113, 2015.

[35] L. S. Wei, W. Wee, J. Y. F. Siong, and D. F. Syamsumir, "Characterization of anticancer, antimicrobial, antioxidant properties and chemical compositions of Peperomia pellucida leaf extract," Acta Medica Iranica, vol. 49, no. 10, pp. 670-674, 2011.

[36] Y. Song and S. K. Cho, "Phytol induces apoptosis and ROSmediated protective autophagy in human gastric adenocarcinoma AGS cells," Biochemistry \& Analytical Biochemistry, vol. 4, article 211, 2015.

[37] R. Amarowicz, "Squalene: a natural antioxidant?" European Journal of Lipid Science and Technology, vol. 111, no. 5, pp. 411412, 2009.

[38] S.-K. Kim and F. Karadeniz, "Biological importance and applications of squalene and squalane," Advances in Food and Nutrition Research, vol. 65, pp. 223-233, 2012.

[39] O. Kunle, J. Okogun, E. Egamana, E. Emojevwe, and M. Shok, "Antimicrobial activity of various extracts and carvacrol from
Lippia multiflora leaf extract," Phytomedicine, vol. 10, no. 1, pp. 59-61, 2003.

[40] A. Ben Arfa, S. Combes, L. Preziosi-Belloy, N. Gontard, and P. Chalier, "Antimicrobial activity of carvacrol related to its chemical structure," Letters in Applied Microbiology, vol. 43, no. 2, pp. 149-154, 2006.

[41] S. A. Burt, V. T. A. Ojo-Fakunle, J. Woertman, and E. J. A. Veldhuizen, "The natural antimicrobial carvacrol inhibits quorum sensing in Chromobacterium violaceum and reduces bacterial biofilm formation at sub-lethal concentrations," PLOS ONE, vol. 9, no. 4, Article ID e93414, 2014.

[42] J. C. Matasyoh, J. J. Kiplimo, N. M. Karubiu, and T. P. Hailstorks, "Chemical composition and antimicrobial activity of essential oil of Tarchonanthus camphoratus," Food Chemistry, vol. 101, no. 3, pp. 1183-1187, 2007.

[43] S. Prachayasittikul, P. Buraparuangsang, A. Worachartcheewan, C. Isarankura-Na-Ayudhya, S. Ruchirawat, and V. Prachayasittikul, "Antimicrobial and antioxidative activities of bioactive constituents from Hydnophytum formicarum Jack," Molecules, vol. 13, no. 4, pp. 904-921, 2008. 


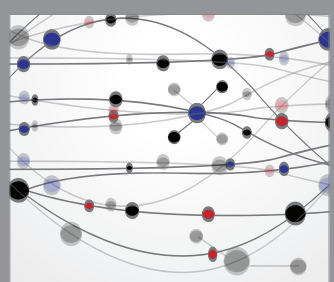

The Scientific World Journal
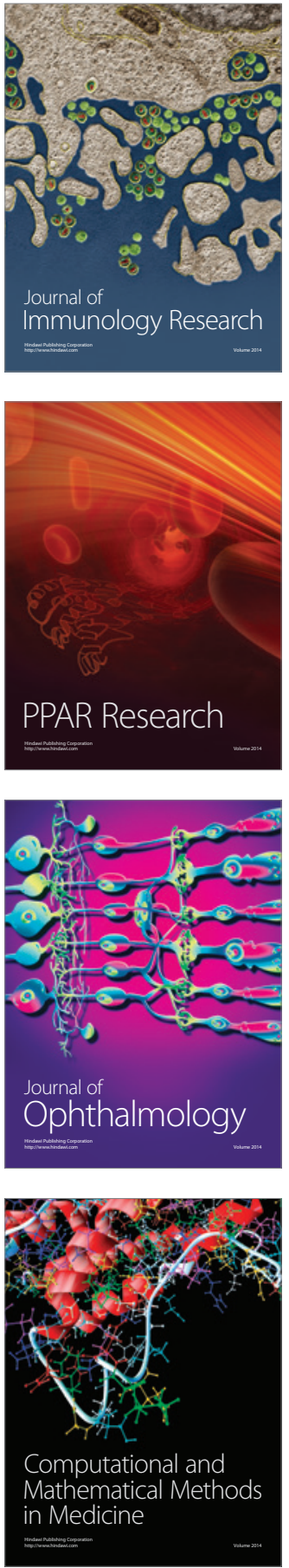

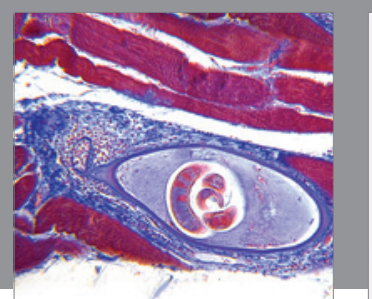

Gastroenterology Research and Practice
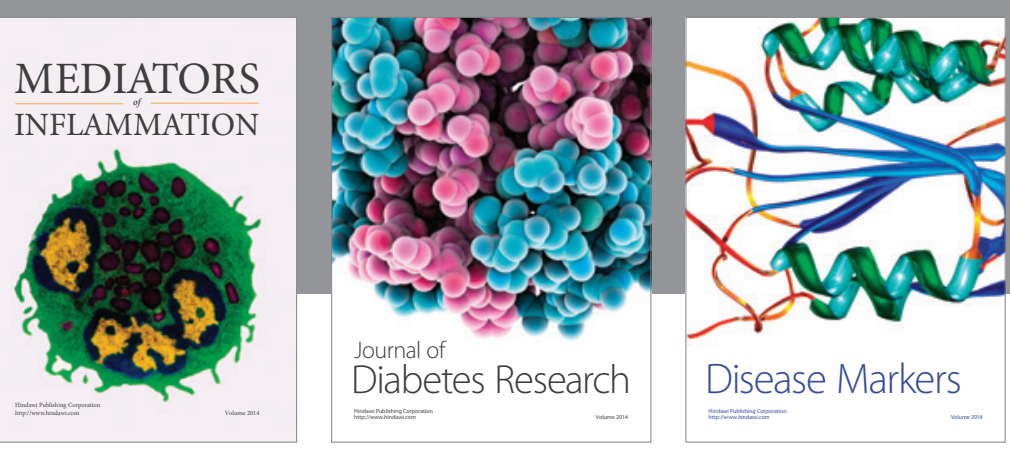

Disease Markers

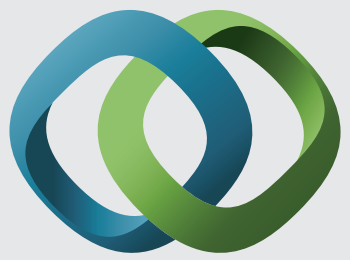

\section{Hindawi}

Submit your manuscripts at

https://www.hindawi.com
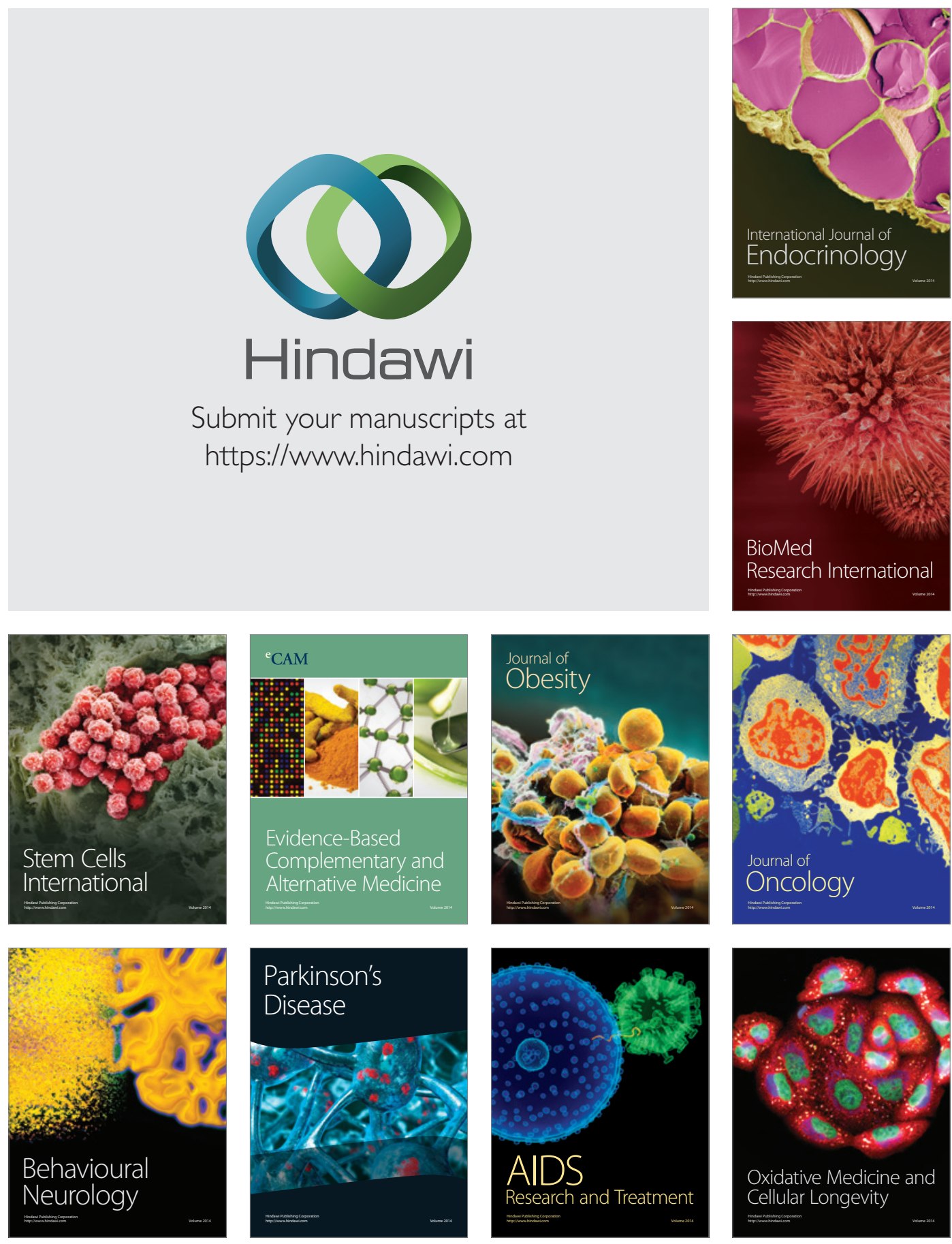